\title{
Experimental hypertrophic neuropathy: an electron microscope study
}

\author{
R. O. WELlER AND T. K. DAS GUPTA* \\ From the Department of Pathology and Anatomy, Guy's Hospital Medical School, London
}

The main clinical features in the human syndrome of hypertrophic neuropathy are thickening of the peripheral nerves, progressive muscular weakness, sensory disturbances, and deformities usually developing over many years. This disease complex together with the histological features of the peripheral nerves was described by Gombault and Mallet in 1889, and further investigated as a familial disease occurring in a brother and sister by Dejerine and Sottas in 1893. Subsequent case descriptions, reviewed by Austin (1956), have shown a wide variation in the age of onset and clinical course of the disease. Many of the recorded cases have a definite family history, although in others no hereditary tendency has been detected.

The histological appearance of the thickened nerves in hypertrophic neuropathies is more characteristic than the clinical signs produced. There is loss of myelin together with cellular hyperplasia and an accumulation of mucoid material within the nerve; the typical 'onion-bulb' whorls are observed when the nerve is cut in cross-section (Dejerine and Sottas, 1893). Electron microscopy has shown that the cellular whorls are composed of imbricated layers of Schwann cells (Dereux, 1963; Dyck, 1966; Garcin, Lapresle, Fardeau, and de Recondo, 1966; Thomas and Lascelles, 1967; Webster, Schröder, Asbury, and Adams, 1967). At the centre of most of the whorls there is a large diameter axon, either myelinated or demyelinated, and in many cases in the process of remyelination (Weller, 1967).

Teased isolated nerve fibres from hypertrophic nerves have shown that the loss of myelin is largely due to segmental demyelination. This observation is supported by the electrophysiological observations of severe slowing of conduction in the affected nerves (Thomas and Lascelles, 1967). These histological appearances are not, however, specific to the classical syndromes of Dejerine and Sottas (1893), or to Refsum's disease, for hypertrophic neuropathy has been described in association with other

* Present address : Gastric and Mixed Tumor Services, Memorial Hospital for Cancer and Allied Diseases, New York, U.S.A. diseases. These include acromegaly (Stewart, 1966) $\frac{\overline{\bar{O}}}{\mathrm{n}}$ diabetes mellitus (Thomas and Lascelles, 1966) and neuromuscular atrophies (Dyck, 1966). $A$ Q localized form of hypertrophic neuropathy has alsâs been described by Simpson and Fowler (1966) $\overrightarrow{0}$ where only a short length of the nerve is affected:The wide variety of conditions under which the $\vec{\omega}$ 'onion-bulb' histological pattern occurs suggests? that the formation of Schwann cell whorls is, to an certain extent, a non-specific change in response to chronic recurrent demyelination; this may be the result of many different aetiological agents (Austip $\vec{i}$ 1956).

The present paper describes how many of the feats ures of hypertrophic neuropathy can be produck experimentally in the rat sciatic nerve. A chrowi demyelinating lesion is induced by the intraneuka? implantation of a relatively insoluble chemiga irritant, 9,10 dimethyl-1,2-benzanthracene (DMBE). The histological appearances of the lesion productad are very similar to those of hypertrophic neuro.90 pathy in man. There is segmental demyelination in which the myelin sheaths are broken down but the axons remain intact, followed by remyelination of many of the affected segments. In this experimento in which the noxious material probably persistsD within the nerve during the recovery stage, remyelina tion takes place accompanied by the formation of 'onion-bulb' whorls of Schwann cells.

\section{MATERIALS AND METHODS}

The right sciatic nerve was exposed in three young adulp white rats under ether anaesthesia, with full aseptic precautions. Approximately $0 \cdot 2 \mathrm{mg}$ pure 9,10 dimethyl 1,2-benzanthracene crystals (Koch-Light Laboratories $\mathcal{B}$ (DMBA) was introdueed through a needle within andB around each nerve fasciculus. One black silk suture was placed in the muscle bed near the site of implantation, to be used for future localization of the lesion. The wound was closed with interrupted plain 4-0 catgut sutures.

All three rats developed a severe flaccid paresis in the injected limb within 4-5 weeks of the operation, but they subsequently began to recover the use of the limb. Af 
14 weeks, when the first rat was sacrificed there was still a very marked paresis; this was less at 22 weeks when the second rat was killed, and recovery was almost complete by the time the nerve was removed from the third rat at 28 weeks.

PREPARATION OF SPECIMENS Specimens of the sciatic nerves were taken from the rats after 14, 22, and 28 weeks. The nerves were re-exposed under ether anaesthesia, and in each case the site of DMBA implantation was encased in inflammatory tissue. The affected lengths of nerve were removed together with the enveloping inflammatory tissue and placed in $3 \%$ glutaraldehyde in 0.067 molar sodium cacodylate buffer at $\mathrm{pH} 7.4$ for $4 \mathrm{hr}$ at $4^{\circ} \mathrm{C}$. Blocks were taken from the proximal and distal ends, and from the central region of the affected lengths of nerve. They were washed in 0.067 molar cacodylate buffer with $7.5 \%$ sucrose at pH 7.4 for $18 \mathrm{hr}$, post-osmicated for $2 \mathrm{hr}$ in $1 \%$ osmium tetroxide in phosphate buffer, dehydrated in graded ethanols, and embedded in Araldite.

Pathological areas of demyelination within the nerves were identified with the light microscope in $1-2 \mu$ Araldite sections stained with $1 \%$ toluidine blue. Thin sections of these areas were subsequently cut on a Huxley Cambridge microtome, stained with uranyl acetate and lead citrate, and viewed in an RCA EMU 3-e electron microscope.

Control sciatic nerves were taken from normal rats and prepared for electron microscopy in the same way as the pathological specimens.

Portions of the pathological nerve were also embedded in paraffin and the sections stained with haematoxylin and eosin for light microscopical study. Teased preparations were stained either in Oil Red $O$ and Meyer's haemalum (Jacobs, 1967) or stained with $1 \%$ osmium tetroxide.

\section{RESULTS}

ELECTRON MICROSCOPY OF NORMAL NERVE The ultrastructure of the normal rat nerve has been described by previous authors (Causey, 1960; Ross, 1964) and is very similar to that of the guinea-pig (Webster and Spiro, 1960), and human infant (Weller, 1967). The larger, myelinated nerves have very little Schwann cytoplasm outside the myelin sheath, except in the peri-nuclear region and near the node of Ranvier. These fibres are separated from each other by collagen and other constituents of the endoneurium. The non-myelinated axons on the other hand form compact groups invaginated into the surface of Schwann (Remak) cells.

Quantitative measurements of mean axon diameters were made on electron micrographs of normal myelinated and non-myelinated nerves (Fig. 1). The myelinated axon diameters are all greater than $1 \mu$ whereas the non-myelinated axons are less than $1 \mu$. Figure 2 is the regression line obtained

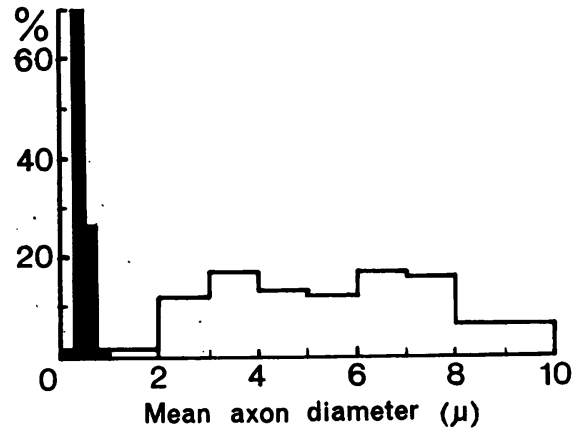

FIG. 1. Histogram to show the frequency distribution of axon diameters. Non-myelinated fibres (black columns) and myelinated nerve fibres (open columns) of normal rat sciatic nerve. No myelinated axons were observed less than $1 \mu$ in diameter, and no non-myelinated axons more than $1 \mu$ in diameter.

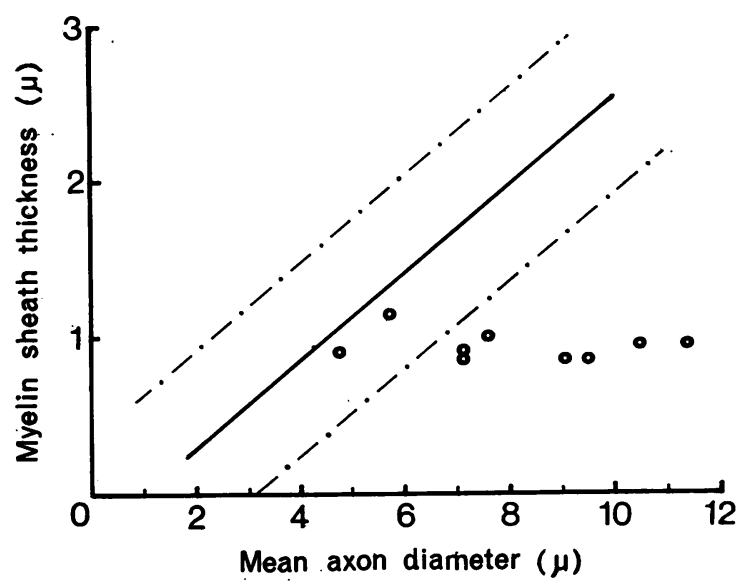

FIG. 2. Mean axon diameters plotted against myelin sheath thickness in normal rat sciatic nerve. Continuous line represents a calculated regression line of myelin width on axon diameter for 100 fibres measured in electron micrographs. The dotted lines are placed two standard errors of estimate $(S y=0.3 \mu)$ on either side of the regression line. Correlation coefficient 0.728. The open circles plotted on the graph represent the myelinated fibres in Fig. 6.

when the mean axon diameter is compared with the myelin sheath thickness.

MACROSCOPIC AND LIGHT MICROSCOPIC OBSERVATIONS OF THE PATHOLOGICAL NERVES There was an intense inflammatory reaction around each of the nerves spreading from the site of the DMBA implantation. The adherent inflammatory tissue formed swellings up to $3 \mathrm{~cm}$ long, completely surrounding the nerve bundles. 
Haematoxylin and eosin stained sections showed that the nerve bundles were still intact but that there was an increase in Schwann cells, particularly in the distal parts of the nerves. No evidence of neoplasia was detected within the nerve or in the inflammatory tissue surrounding it.

The majority of the myelinated fibres were normal in the proximal parts of the affected nerve. There were, however, some areas of gross myelin loss, observed in the $1 \mu$ Araldite sections stained with toluidine blue. This loss was most pronounced in the regions of the nerve just inside the perineurium, where the fibres were in close proximity to the extra-fascicular inflammatory tissue mass. The distal ends of the nerve showed changes mainly of Wallerian degeneration.

TEASED PREPARATIONS A gross increase in cells was observed in the Oil-Red-O-haemalum preparations of the affected nerves. Most of these cells appeared to be Schwann cells, although macrophages containing globular droplets were also common. The individual fibres were difficult to separate, as many had sheaths of cells enclosing them. Segmental demyelination was observed in the Oil-Red-O and in the osmium stained preparations. Many thinly myelinated fibres were observed, often enclosed in cylindrical cellular sheaths similar in appearance to those observed in hypertrophic neuropathy in man (Cavanagh, 1966; Thomas an Lascelles, 1967).

ELECTRON MICROSCOPY OF THE PATHOLOGICAL NERVES Examination of transverse sections of the sciati nerves in the areas of DMBA implantation revealed some areas of gross myelin loss, although the major? ity of the fibres were normal.

The major lesion observed within the nerves was segmental demyelination, a process described by. Gombault (1880) in chronic lead neuropathy. The myelin sheath breaks down, whereas the axon remains intact and subsequent remyelination fres quently occurs. In the present study, there was i addition some axonal degeneration. The axonat loss was most prominent at the distal end of the nerve where there was a cumulative effect from the Wallerian degeneration throughout the injected region.

SEGMENTAL DEMYELINATION Many of the differen? stages of segmental demyelination, that have beep described in diphtheritic segmental demyelination (Weller, 1965), were detected throughout the affected lengths of nerve. The early phases weres observed where large demyelinated axons were devoid of myelin sheaths (Fig. 3) and were meriply enclosed by a layer of Schwann cell. The mysin debris was often present in vacuoles within tho

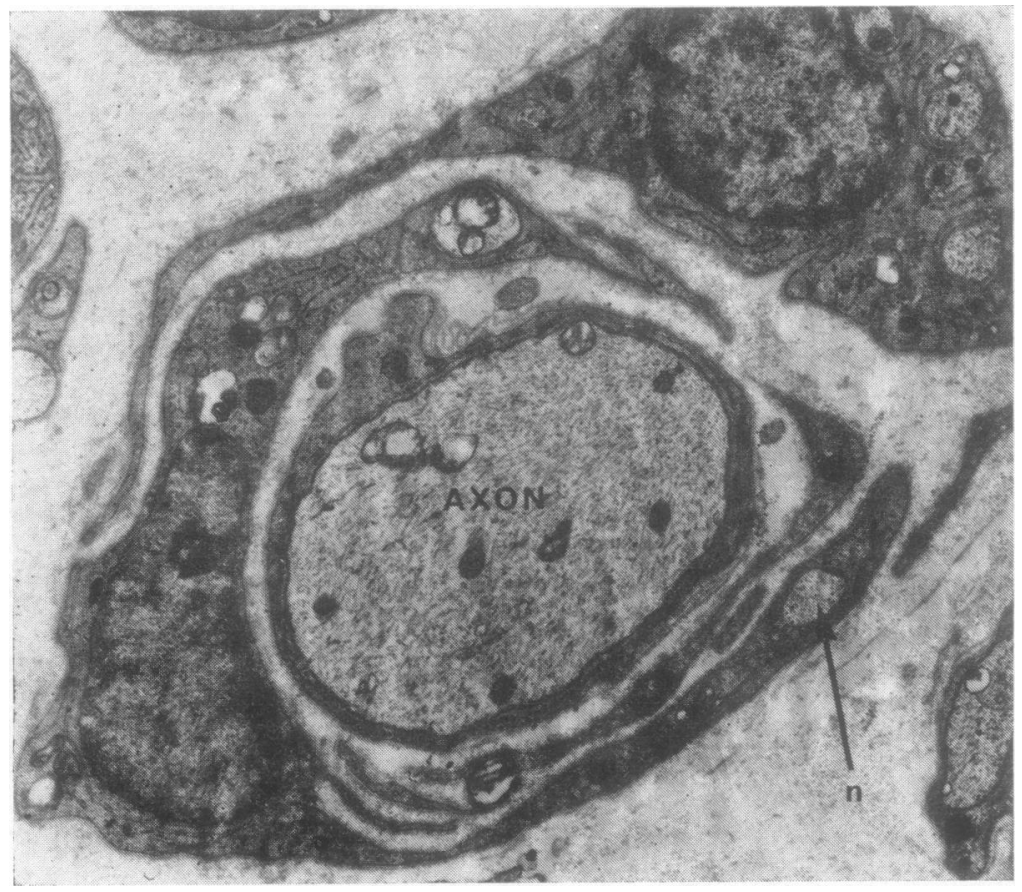

FIG. 3. Electron micrograph T.\$్ of $D M B A$ injected nerve (22 weeks). The central demyelinated $7 \mu$ axon has no myelin sheath but there is a layer of Schwann cell ang one turn of mesaxon (early remyelination) around it. Ramak cells containing non myelinated axons ( $n$ ) form a whorl around the central nerve fibre. $\times 8,500$. 


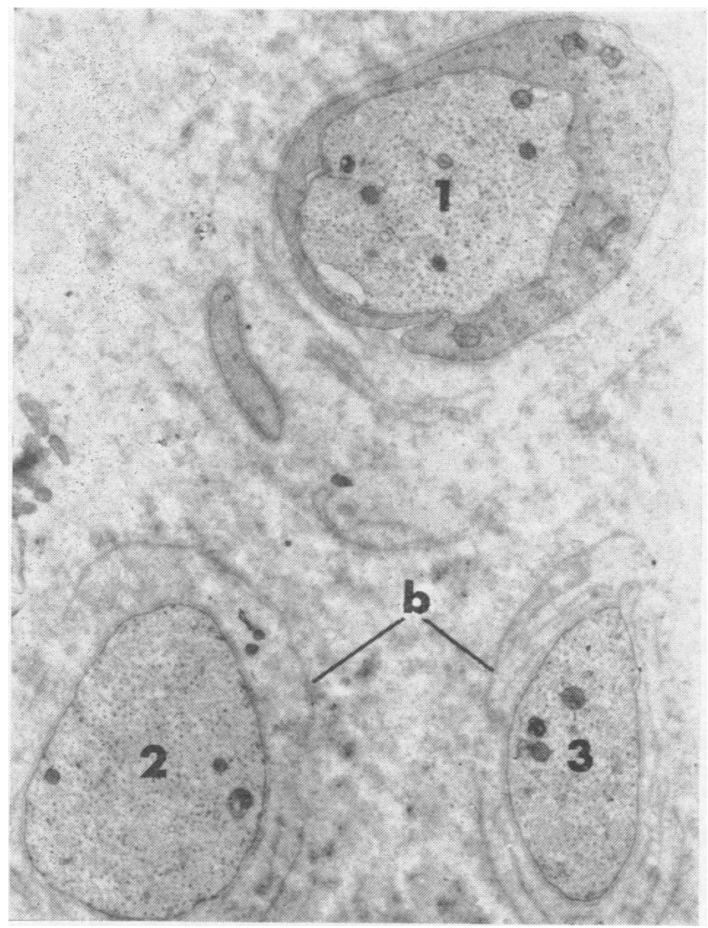

FIG. 4. Electron micrograph T.S. of DMBA injected nerve (22 weeks). Three demyelinated axons are seen 3-4 $\mu$ in diameter: only one of the axons (1) is surrounded by Schwann cell and the others (2 and 3) are naked except for a covering of basement membrane. Further basement membrane whorls are surrounding these fibres $(b) . \times 7,000$.

Schwann cytoplasm, completely separate from the axon. Similar myelin-containing vacuoles in diphtheritic neuropathy have been shown to contain lysosomal enzymes (Weller and Mellick, 1966). Some of the axons, which by their diameter of $2-4 \mu$ were probably once myelinated, had no Schwann cytoplasm surrounding them, only a basement membrane (Fig. 4). This stage of severe Schwann cell retraction has been observed in human hypertrophic neuropathy (Weller, 1967). The 'naked' axons in Fig. 4 were part of a group of six closely related axons with little or no Schwann cell around them. It is improbable that this appearance represents a transverse section through the mid-plane of normal nodes of Ranvier, for none of the specialized cytoplasmic processes that usually characterize a node of Ranvier (Landon and Williams, 1963) were present. Furthermore, normal nodes of Ranvier are not usually so closely aligned in a transverse plane. It is probable, therefore, that the gaps between the consecutive Schwann cells along these particular nerves were considerably increased.
Despite the retraction of the satellite Schwann cells however, the axons in Fig. 4 appeared structurally normal and showed none of the signs usually associated with the early stages of axonal degeneration (Holtzman and Novikoff, 1965; see below).

REMYELINATION Remyelination was observed in many of the fibres, ranging from a few turns of non-compacted mesaxon, through the stages of compaction and increase in myelin thickness described in both normal myelination (Geren, 1954; Cravioto, 1966) and in remyelination in acute neuropathies (Webster, Spiro, Waksman, and Adams, 1961), and in chronic neuropathies (Weller, 1967). The process of remyelination was quite obvious in transverse sections during the early stages where large axons were encompassed by very thin myelin sheaths, but in the later stages (Fig. 5) it was necessary to estimate the axon-myelin ratio and compare it with the normal. When the fibres in Fig. 5 are plotted on the graph (Fig. 2) it is seen that the myelin thickness is approximately the same for a wide range of axon diameters. It is possible either that the remyelination was not complete or that the mature sheath thickness was not regained in these nerves.

WALLERIAN DEGENERATION Electron microscopic examination of the distal ends of the affected nerves revealed extensive axonal degeneration (Fig. 6). There were many Schwann cells, identifiable by their basement membranes, but the numbers of both myelinated and non-myelinated axons were severely reduced. Evidence of axonal regeneration was detected with small axons, $1 \mu$ or less in diameter, in the process of remyelination (Fig. 7) with several turns of non-compacted mesaxon within a thin layer of compact myelin. These were probably regenerating sprouts similar to those seen during regeneration after a simple nerve crush (Nathaniel and Pease, 1963), for although they were myelinated, the axonal diameter was too small for a normal myelinated axon (Fig. 1).

Throughout the more proximal parts of the nerve, scattered fibres were in various stages of Wallerian degeneration. The axonal changes ranged from the early accumulation of lamellated figures and vesicles within the axoplasm (Webster, 1962; Holtzman and Novikoff, 1965), to the later stages where the axon had degenerated and only the Schwann cells remained, very often containing remains of the myelin sheath.

HYPERTROPHIC FEATURES Cellular arrangements very similar to those in the 'onion-bulb' whorls of human hypertrophic neuropathy were observed, 


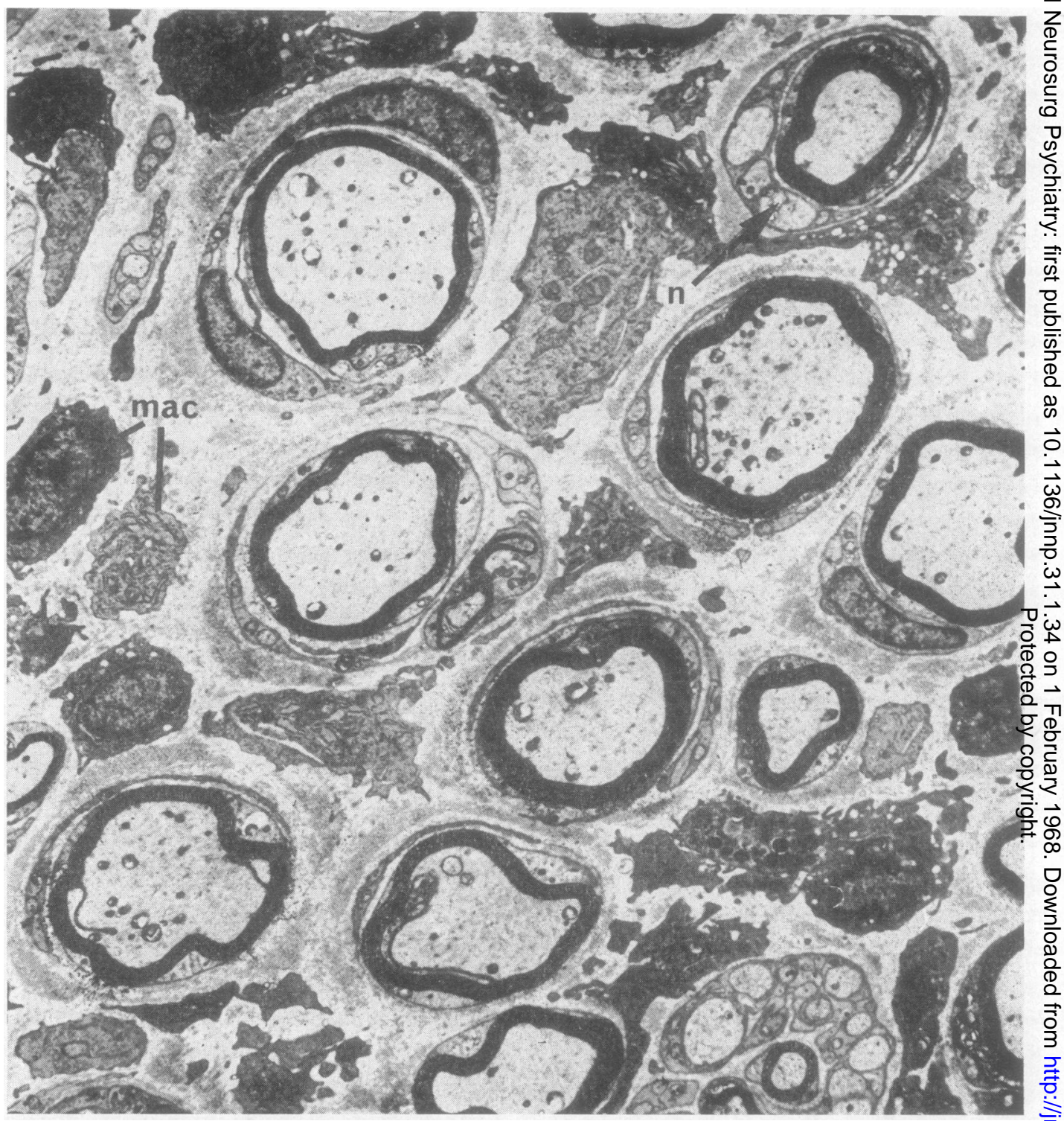

FIG. 5. Electron micrograph DMBA injected nerve (28 weeks). Most of the myelinated fibres are surrounded by cellula whorls; some of the cells forming the whorls contain either non-myelinated axons $(n)$ or myelinated fibres. Endoneuria $\bar{P}$ macrophages $(\mathrm{mac}) \times 2,550$. The axon, myelin sheath relationships are plotted on Fig. 2 .

especially in the proximal parts of the affected region of each nerve. The whorls consisted of Remak or Schwann cells often containing non-myelinated, and occasionally, myelinated axons (Figs. 3, 5, 8, 9). The cells were arranged in layers most frequently around remyelinating fibres. There was some variation in the precise arrangement of the cells forming the whorls. In many cases the cell processes overlapped and formed a similar pattern to that found in human hypertrophic neuropathy (Fig. 3). Howê ever, in other whorls, the Schwann or Remak celk processes almost or completely encircled the centrag nerve fibre (Figs. 8 and 9). The Remak cell forming the concentric whorl in Fig. 9 could have been con fused with a perineurial cell, but it did not form the terminal bars that are typical of perineurial cells? Furthermore, it contains an invaginated non ${ }_{0}$ myelinated axon which is typical of a Remak cell 


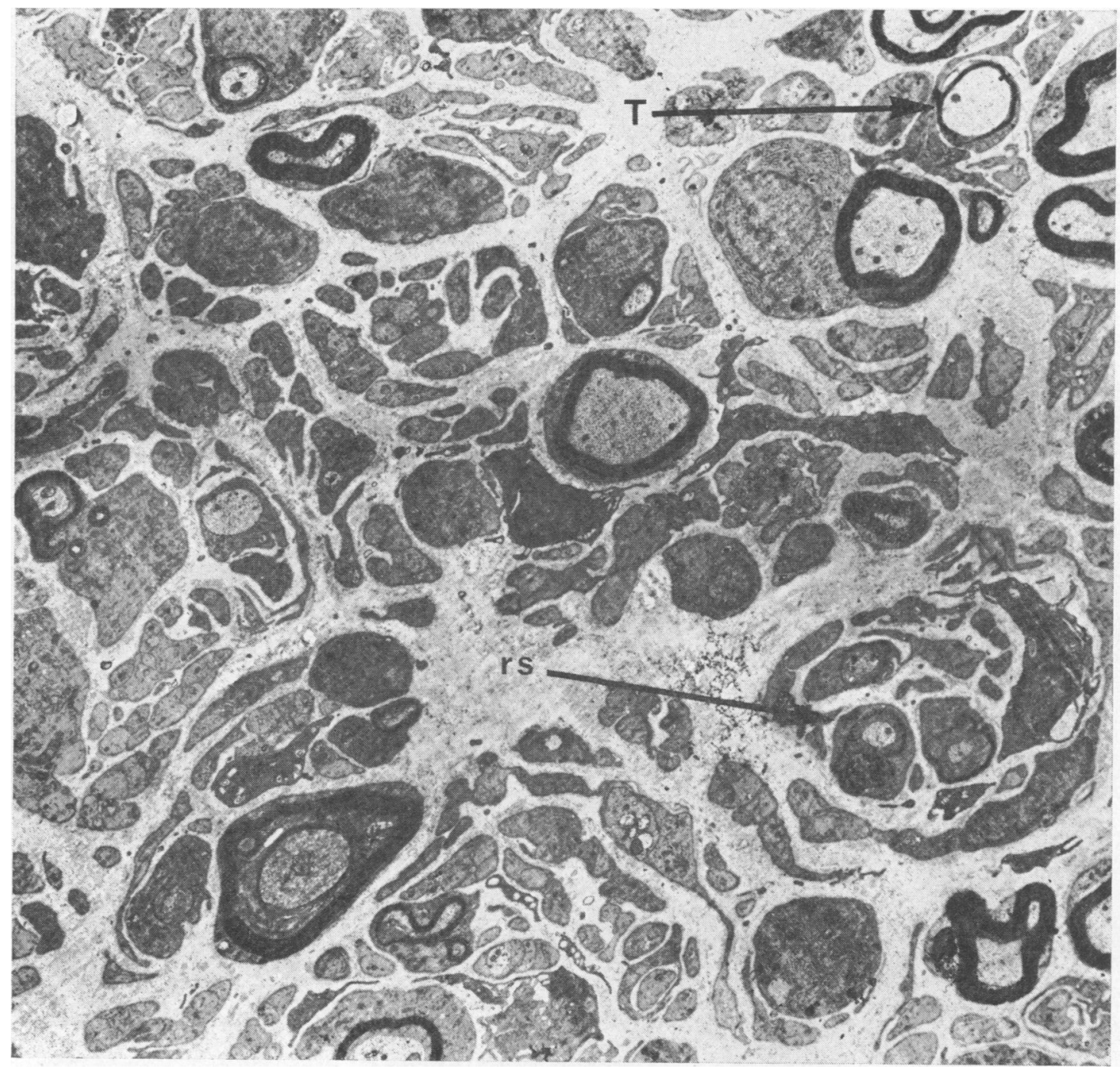

FIG. 6. Electron micrograph of DMBA injected nerve (22 weeks). This area from the distal end of the affected region contains very few myelinated fibres and shows extensive axonal loss with many free Schwann cells. Some myelin sheaths are relatively very thin $(T)$, and there is some whorl formation around regenerating sprouts $(r s) \times 2,$.550 .

The encirclement of the myelinated fibre in Fig. 9 is complete, with continuity of the layers of basement membrane throughout. Another noteworthy feature in Fig. 9 is that the intercellular spaces between the central Schwann cell and the layers of Remak cell encircling it, are almost completely devoid of collagen. This feature was a frequent finding when the cellular whorls completely surrounded the central fibre.

The centre of the cellular whorl was usually occupied by one or more axons that had either lost its myelin sheath (Fig. 3), was showing evidence of remyelination (Fig. 5) or appeared to be normal (Fig. 8). Occasionally a whorl with no axon at the centre was observed, but there was usually some evidence of recent Wallerian degeneration such as macrophage containing myelin debris adjacent to the central Schwann cell. In areas where there was extensive Wallerian degeneration and axonal loss, there were very few whorls (Fig. 6) and then they were usually only around remyelinating fibres or regenerating axonal sprouts which were also mye- 


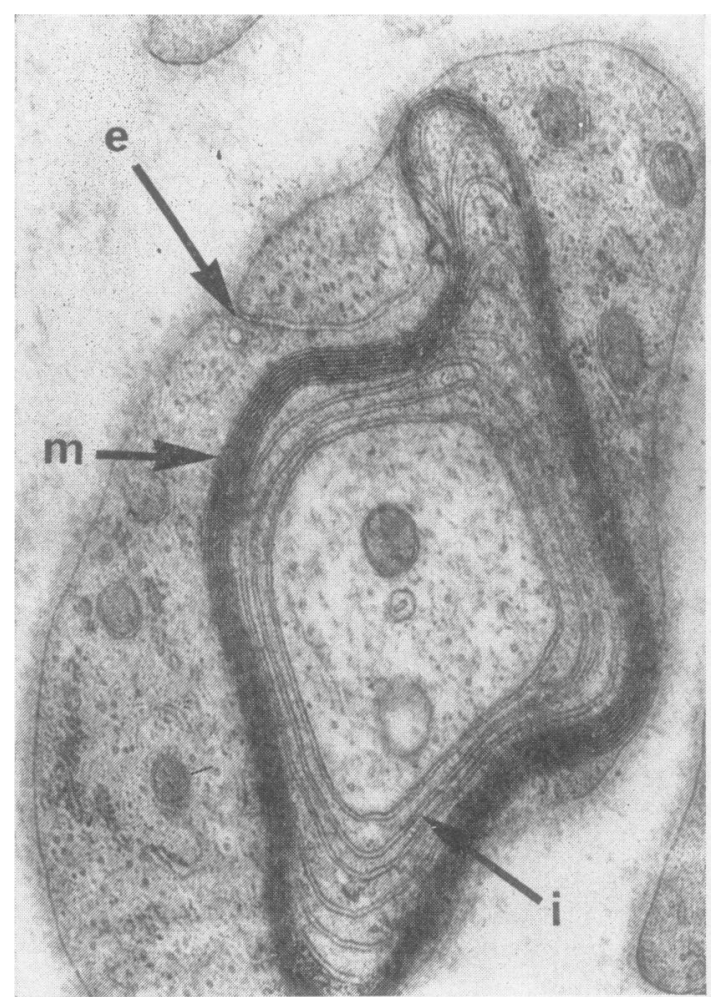

FIG. 7

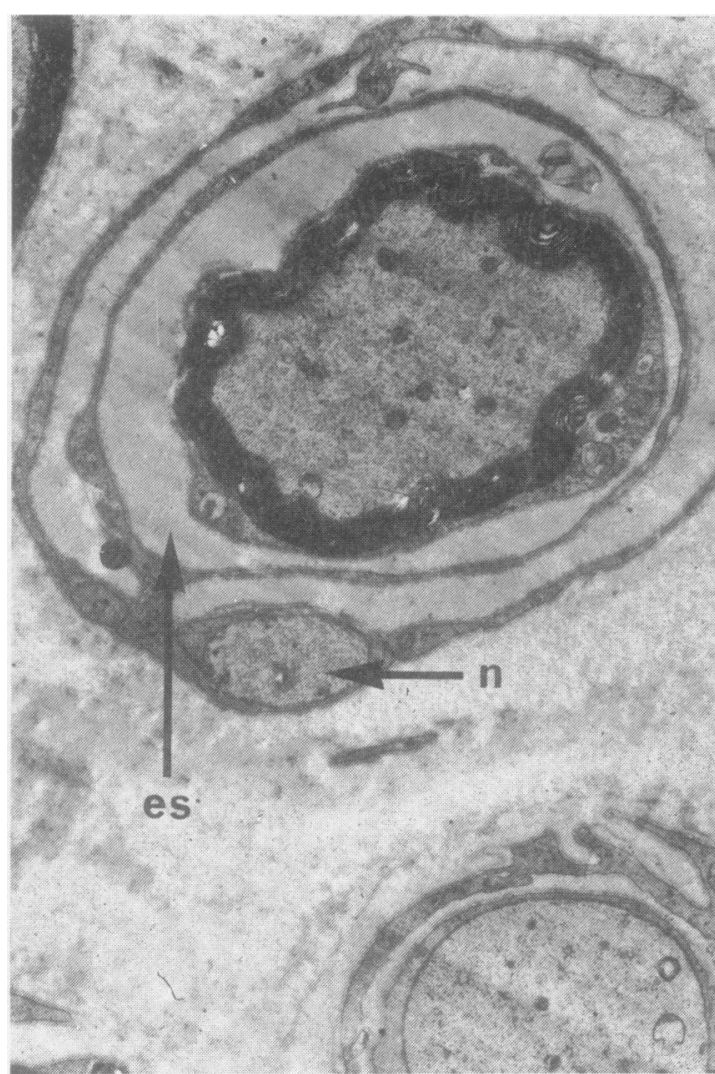

FIG. 9

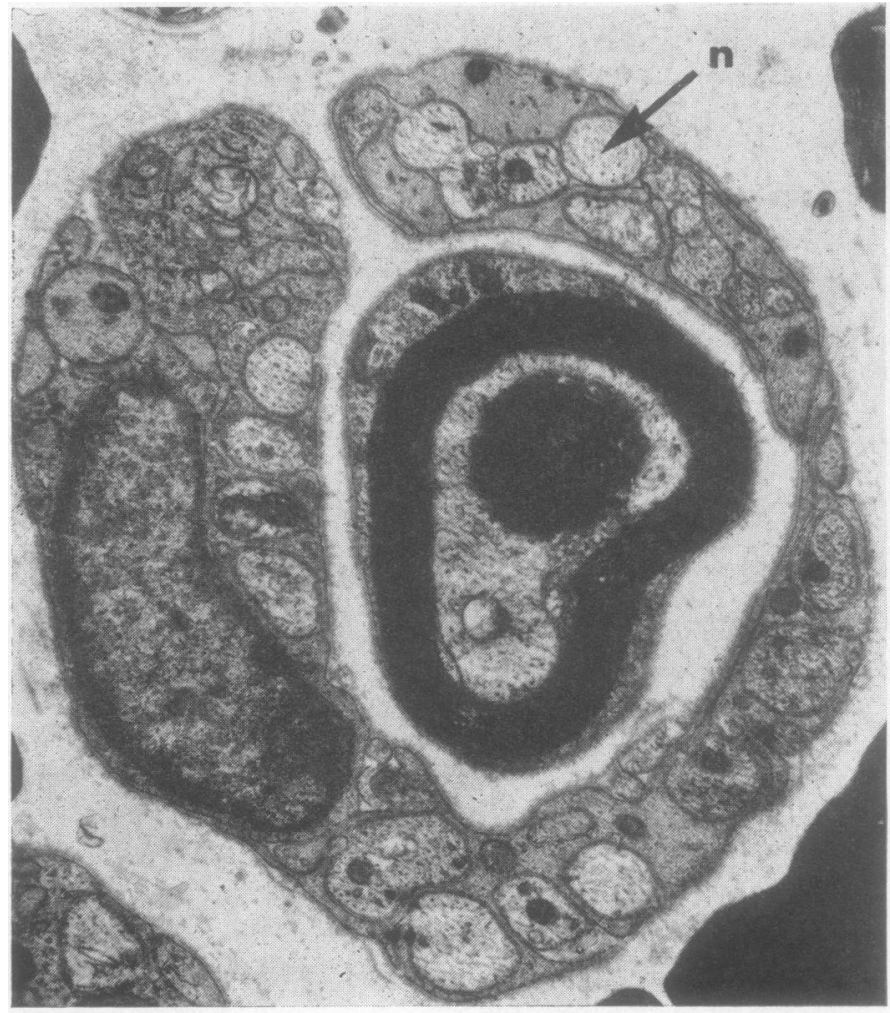

FIG. 7. Electron micrograph of regenerating 망 sprout undergoing myelination from a similar ared to Fig. 6. The axon is less than $1 \mu$ in diametep and there are several turns of non-compacted internal mesaxon $(i)$. Compact myelin $(m)$, external mesaxon $(e) . \times 32,000$.

FIG. 8. Myelinated fibres almost completely encircled by a Remak cell containing nonmyelinated axons $(n) . \times 15,000$.

FIG. 9. Two layers of Remak cell completely surrounding a myelinated axon. Non-myelinated axon $(n)$. There is very little collagen within the inner endoneurial space (es). A demyelinated at bottom of picture. $\times 11,200$. 
linating. Another noticeable feature was the absence of whorls associated with the 'naked' fibres (Fig. 4). In this situation, however, there were often several layers of basement membrane around the axons, suggesting that cellular processes may have once surrounded the axons and had been subsequently retracted.

\section{DISCUSSION}

The main peripheral nerve lesion produced by the implantation of a sparingly soluble chemical irritant, DMBA, into the rat sciatic nerve was segmental demyelination, but there was some axonal degeneration. The early stages of myelin sheath breakdown in the affected nerve fibres appeared to follow a similar course to that observed in ultrastructural studies of acute diphtheritic segmental demyelination (Weller, 1965; Weller and Mellick, 1966). The myelin sheath became separated from the axon, but, whereas the latter was usually preserved, the disorganized myelin sheath was destroyed by the Schwann cell or by macrophages. Not all the fibres in the DMBA-injected nerves underwent segmental demyelination at the same time, and, while myelin breakdown was occurring in some fibres, other, closely related fibres were already remyelinating; a similar situation was observed in human hypertrophic neuropathy (Weller, 1967). This suggests that the stimulus for segmental demyelination may have persisted within the nerve fasciculi producing chronic and possibly recurrent demyelination.

The other major similarity between the DMBA injected nerves in this study and human hypertrophic neuropathy was the formation of whorls composed of Schwann and Remak cells. The whorls in the experimental lesion had a very similar cellular arrangement to those of the human disease. However, they were smaller and had fewer layers in the experimental lesion which may have been due to the relatively short duration of the DMBA neuropathy. The most distinct whorls were observed around the remyelinating fibres, and they were uncommon in the distal part of the nerve where there was gross loss of axons following Wallerian degeneration.

The exact mode of action of the carcinogen DMBA upon Schwann cells cannot be assessed from the present observations; its effect may have been directly upon the metabolism of the cells, or possibly through an indirect modification of the environment. The gross inflammatory reaction around the DMBA injected nerves may have produced ischaemia with subsequent segmental demyelination, similar to that occurring in the limb nerves with occlusive vascular disease in man (Garven, Gairns, and Smith, 1962; Chopra and Hurwitz, 1967; Eames and Lange, 1967).
There was, in some instances, a marked retraction of the affected Schwann cells resulting in bare areas along the axons. It is possible that these naked axons might subsequently have degenerated, either as a direct result of Schwann cell retraction, or from the action of other environmental factors mentioned above, and so contributed to the overall picture of axonal loss at the distal end of the nerve.

Remyelination in many cases appeared to have commenced soon after the myelin sheath had been disrupted; this is also a feature of acute diphtheritic demyelination (Cavanagh and Jacobs, 1964) and it appears that in both cases the Schwann cell may rapidly recover from the primary toxic insult.

The significance of the 'onion-bulb' whorl formation was difficult to assess. The majority of the Schwann or Remak cell whorls were related to remyelinating fibres as in the human disease (Weller, 1967). The cells within the whorls frequently formed a layer completely encircling the central nerve fibre, with the exclusion of collagen from the endoneurial space immediately surrounding the remyelinating nerve. The Schwann and Remak cells that formed the whorl might influence or modify the endoneurial space immediately surrounding the central remyelinating fibres. This would possibly have had some protective effect in the present experimental system, for the chemical irritant probably persisted within the nerve fasciculi and was, in fact, often observed in endoneurial macrophages.

One modification of the endoneurial space in human hypertrophic neuropathy that has not been studied in the experimental system is the accumulation of large quantities of mucoid material within the nerve fasciculi. Preliminary histochemical studies on human hypertrophic nerves suggest that this substance is mainly hyaluronic acid (Weller and Adams, 1967).

There is no information available, as yet, concerning the exact causation of demyelination in human hypertrophic neuropathy. A biochemical abnormality has been observed in Refsum's disease in which hypertrophic neuropathy is a prominent feature. Klenk and Kahlke (1963) found a gross increase in the amount to a branch chain fatty acid, phytanic acid, in the lipids of various organs from these patients. This finding is probably due to an error in tetramethylhexadecanoic acid metabolism (Stoffel and Kahlke, 1965), although its correlation with hypertrophic neuropathy is not clear. The experimental production of hypertrophic neuropathy reported here, in fact, supports the hypothesis that this particular histological appearance is a nonspecific cellular reaction associated with chronic recurrent segmental demyelination.

The presence of tumour cells within the endo- 
neurial space (Kashef and Das Gupta, 1967) is also associated with segmental demyelination, and in this study it has been shown that persistent chemical irritation results in chronic segmental demyelination. The role of the contents of the endoneurium, including the blood-vessels together with the cells and humoral agents derived from the blood, has yet to be assessed in chronic, recurrent neuropathies and should be considered in addition to the possible inherent abnormalities of Schwann cells.

Further investigation is required concerning the influence of endoneurial components upon nerve fibres and the way in which Schwann or Remak cell whorls or sheaths may modify the immediate environment of the remyelinating Schwann cells. The experimental model for hypertrophic neuropathy proposed in this paper may be useful in these investigations.

\section{SUMMARY}

A sparingly soluble chemical irritant, 9,10 dimethyl1,2-benzanthracene (DMBA), was implanted into and around the sciatic nerves of three young adult rats. A severe inflammatory reaction was produced and segmental demyelination together with some axonal degeneration was observed. Distinct Schwann and Remak cell whorls were observed with the electron microscope around the remyelinating fibres. The cellular arrangement was similar to that seen in human hypertrophic neuropathy.

We would like to express our gratitude to Drs. P. L. Williams, C. Wendell-Smith, and J. B. Cavanagh for their advice and criticism. One author (R.O.W.) was supported by the Multiple Sclerosis Society and the National Fund for Research into Poliomyelitis and Other Crippling Diseases. The electron microscope was made available by the National Spastics Society.

\section{REFERENCES}

Austin, J. H. (1956). Observations on the syndrome of hypertrophic neuritis. Medicine (Baltimore), 35, 187-237.

Causey, G. (1960). The Cell of Schwann. Livingstone, Edinburgh.

Cavanagh, J. B. (1966). Personal communication.

- , and Jacobs, Jean M. (1964). Some quantitative aspects of diphtheritic neuropathy. Brit. J. exp. Path., 45, 309-322.

Chopra, J. S., and Hurwitz, L. J. (1967). Internodal length of sural nerve fibres in chronic occlusive vascular disease. J. Neurol. Neurosurg. Psychiat., 30, 207-214.

Cravioto, H. (1966). Electron microscopy of the myelination of the human fetus. Proc. fifth int. Congr. Neuropath., Zurich, 1965, ed. A. Bischoff and F. Lüthy pp. 744-746. (Int. Cogr. Ser. No. 100) Excerpta Medica Foundation, Amsterdam.

Dejerine, J., and Sottas, J. (1893). Sur la névrite interstitielle, hypertrophique et progressive de l'enfance. C.R. Soc. Biol. (Paris), 45 (ser. 9, 5), 63-96.

Dereux, J. (1963). La maladie de Refsum. Rev. neurol., 109, 599-608.

Dyck, P. J. (1966). Histologic measurements and fine structure of biopsied sural nerve: normal, and in peroneal muscular atrophy, hypertrophic neuropathy, and congenital sensory neuropathy. Mayo Clin. Proc., 41, 742-774.
Eames, Rosemary A., and Lange, L. S. (1967). Clinical and patho으 logical study of ischaemic neuropathy. J. Neurol. Neurosurg.Z Psychiat., 30, 215-226.

Garcin, R., Lapresle, J., Fardeau, M., and de Recondo, J. (1966). Etude au microscope électronique du nerf périphérique@ prélevé par biopsie dans quatre cas de névrite hypertrophique de Dejerine-Sottas. Rev. neurol. 115, 917-932.

Garven, H. S. D., Gairns, F. W., and Smith, G. (1962). The nerve fibre populations of the nerves of the leg in chronic occlusive arterial disease in man. Scot. med. J., 7, 250-265.

Geren, B. B. (1954). The formation from the Schwann cell surface of myelin in the peripheral nerves of chick embryos. Exp. Cell Res., 7, 558-562.

Gombault, A. (1880). Contribution a l'étude anatomique de $1 a^{*}$ névrite parenchymateuse subaiguẻ et chronique-névrite segmentaire péri-axile. Arch Neurol. (Paris). 1, 11-38. 177-190.

Gombault, A., and Mallet (1889). Un cas de tabès ayant débuté danso l'enfance: Autopsie. Arch. Med. exp., 1, 385-415.

Holtzman, E., and Novikoff, A. B. (1965). Lysosomes in the rat sciatic nerve following crush. J. Cell Biol., 27, 651-669.

Jacobs, Jean M. (1967). Experimental diphtheritic neuropathy in $\mathbb{Q}$ the rat. Brit. J. exp. Path., 48, 204-216.

Kashef, R., and Das Gupta, T. K. (1967). Segmental demyelinationes of peripheral nerves in the presence of malignant tumours:An electron microscopic study. Brit. J. Cancer, 21, 411-417.

Klenk, E., and Kahlke, W. (1963). Uber das Vorkommen der 3, 7, 11, 15-Tetramethyl-hexadecansäure (Phytansäure) in den Chole- $\vec{\omega}$ sterinestern und anderen Lipoidfraktionen der Organe beiO einem Krankheitsfall unbekannter Genese (Verdacht auf Heredopathia atactica polyneuritiformis [Refsum-Syndrom].) Z. physiol. Chem. 333, 133-139.

Landon, D. N., and Williams, P. L. (1963). Ultrastructure of the node of Ranvier. Nature (Lond.), 199, 575-577.

Nathaniel, E. J. H., and Pease, D. C. (1963). Regenerative changes. in rat dorsal roots following Wallerian degeneration. $\sigma \cdot \omega$ Ultrastruct. Res., 9, 533-549.

Ross, L. L. (1964). In Electron Microscopic Anatomy, edited by S. Kurtz, pp. 341, 367. Academic Press, New York and Londōn..

Simpson, D. A., and Fowler, M. (1966). Two cases of localized TT hypertrophic neurofibrosis. J. Neurol. Neurosurg. Psychig.,D 29, 80-84.

Stewart, B. M. (1966). The hypertrophic neuropathy of acromegady: A rare neuropathy associated with acromegaly. Arch. Neurgl (Chic.), 14, 107-110.

Stoffel, W., and Kahlke, W. (1965). The transformation of physi into 3,7,11,15-tetramethylhexadecanoic (phytanic) acid Ino heredopathia atactica polyneuritiformis (Refsum's syndrome) $\infty$ Biochem. biophys. Res. Commun., 19, 33-36.

Thomas, P. K., and Lascelles, R. G. (1966). The pathology of diabetico neuropathy. Quart. J. Med., 35, 489-509.

- - (1967). Hypertrophic neuropathy. Quart. J. Med., 36, 223-238.

Webster, H. de F. (1962). Transient, focal accumulation of axonal mitochondria during the early stages of Wallerian degeneration. (8) J. Cell Biol., 12, 361-383.

, and Spiro, D. (1960). Phase and electron microscopic studies $\overrightarrow{\vec{O}}$ of experimental demyelination. I. Variations in myelin sheath contour in normal guinea pig sciatic nerve. J. Neuropath. exp. Neurol., 19, 42-69.

,-- Waksman, B., and Adams, R. D. (1961). Phase and electrono microscopic studies of experimental demyelination. II. Schwann cell changes in guinea pig sciatic nerves during experimental diphtheritic neuritis. Ibid., 20, 5-34.

_- Schröder, J. M., Asbury, A. K., and Adams, R. D. (1967). The? role of Schwann cells in the formation of 'onion-bulbs' found in chronic neuropathies. J. Neuropath. exp. Neurol., 26, 276-299.

Weller, R. O. (1965). Diphtheritic neuropathy in the chicken: An음 electron-microscope study. J. Path. Bact., 89, 591-598.

- (1967). An electron microscopic study of hypertrophic neuro-O pathy of Dejerine and Sottas. J. Neurol. Neurosurg. Psychiat.,

30, 111-125.
-, and Mellick, R. S. (1966). Acid phosphatase and lysosome activity in diphtheritic neuropathy and Wallerian degeneration. Brit. J. exp. Path., 47, 425-434.

—, and Adams, C. W. M. (1967). Unpublished observation. 